\title{
Internet of Things Applied in Healthcare Based on Open Hardware with Low-Energy Consumption
}

\author{
Leonardo Juan Ramirez Lopez ${ }^{1}$, Gabriel Puerta Aponte ${ }^{1}$, Arturo Rodriguez Garcia ${ }^{2}$ \\ 'TIGUM Research Group, Universidad Militar Nueva Granada, Bogota, Colombia \\ ${ }^{2}$ GINT Research Group, Universidad de Santiago de Chile, Santiago, Chile
}

Objectives: The Internet of Things (IoT) and its applications are growing simultaneously. These applications need new intelligent devices along heterogeneous networking. Which makes them costly to implement indeed. Platforms and open devices designed for open-source hardware are possible solutions. This research was conducted under an IoT design, implementation, and assessment model for the remote monitoring of pulse oximetry via oxygen partial saturation $\left(\mathrm{SpO}_{2}\right)$ and heart rate (HR) with low-energy consumption. Methods: This study focused on the development of $\mathrm{SpO}_{2}$ and $\mathrm{HR}$ measurements that will allow the monitoring and estimation in real time of the user's state and health related to the established parameters. Measurements were acquired and recorded using a remote web server that recorded the acquired variables for further processing. The statistical analysis data allows comparison of the registered data measured with theoretical models. Results: The IoT model was developed use Bluetooth low-energy devices, which comply with low-cost and open-hardware solutions operated via 'HTTP requests' for data transmission and reception from a cloud server to an edge device. Network performance assessment was conducted to guarantee the availability and integrity of the acquired values and signals. The system measured $\mathrm{SpO}_{2}$ and $\mathrm{HR}$ variables. The most significant result was to achieve energy consumption $20 \%$ lower than that of devices in the market. Conclusions: In summary, the acquired data validation based on the IoT model had a transmission error of $0.001 \%$ which proves its applicability in healthcare.

Keywords: Internet, Healthcare, Physiologic Monitoring, Remote Sensing Technology, Pulse Oximetry

Submitted: February 21, 2019

Revised: 1st, February 22, 2019; 2nd, April 13, 2019; 3rd, May 4, 2019 Accepted: May 13, 2019

\section{Corresponding Author}

Leonardo Juan Ramirez Lopez

TIGUM Research Group of Universidad Militar Nueva Granada, Carrera 11 \#101-80, Bogota 110111481, Colombia. Tel: +57-16500000,E-mail: leonardo.ramirez@unimilitar.edu.co (https://orcid. org/00000-0002-6473-5685)

This is an Open Access article distributed under the terms of the Creative Commons Attribution Non-Commercial License (http://creativecommons.org/licenses/by$\mathrm{nc} / 4.0 /$ ) which permits unrestricted non-commercial use, distribution, and reproduction in any medium, provided the original work is properly cited.

(C) 2019 The Korean Society of Medical Informatics

\section{Introduction}

Internet of Things (IoT) systems are considered by some authors to constitute the fourth (4.0) industrial revolution, promising several changes in all aspects of human life [1]. Over the last decade, the IoT paradigm [2] has boosted scientific interest in diverse applications and economy fields as well as in various populations; thus, it has become a globally innovating technology trend. IoT has gradually become a part of health, agriculture, and industrial research [3].

There are multiple IoT application scenarios. Devices or physical/virtual things are used to perform functions or recognize the physical world and its context, for example, in home services and intelligent industries, health care ser- 
vices, self-care, environmental monitoring, logistics, defense, transportation and safety $[4,5]$.

These technologies may become adaptability catalysts, leading to the evolution of a new generation of services and devices that will dominate technological and social ecosystems [6]. It is possible to foresee that the systems and services conceived by these next-generation technologies will absorb various domains, such as home healthcare, clinical healthcare, medical follow-up, online government services, transportation, supply chains, energy supply, and other essential public services $[7,8]$.

The development of next-generation devices and services results in the increased generation of huge amounts of data that must be stored, processed, analyzed and presented in an efficient, transparent, and easy-to-interpret way [9]. For this purpose, the systems in the cloud will provide the necessary infrastructure for the processing and subsequent presentation of the supplied information. In this way, they will integrate large sections of monitoring, storage, analysis, visualization, and delivery of information to the final user $[10,11]$. The trends indicate that the healthcare and medical industry will support and encourage the growth of these new technologies, based on the precedent of the cost of implementation and operation of devices. In this context, IoT technologies can establish an impact point for health control via an affordable and efficient method [12].

Pulse oximetry was first implemented in 1972 by Takuo Aoyagi [13]. Since its introduction, it has been based on arterial oxygen saturation $\left(\mathrm{SaO}_{2}\right)$. This method has become crucial for the clinical routine, because it provides important information about the cardiovascular function of patients. Pulse oximetry can use two types of measurements, namely, the $\mathrm{SaO}_{2}$, which is a direct measurement of the oxygen contents, and the blood oxygen saturation $\left(\mathrm{SpO}_{2}\right)$, which is an indirect measurement of the blood oxygen $[14,15]$. The $\mathrm{SpO}_{2}$ is one of the vital survival parameters; it is used in the follow-up of elderly patients and newborns, among others [16]. This method is complemented by the measurement of heart rate (HR); this is the repetition in a time interval of the beats generated by the heart (heartbeats). These heartbeats are produced because the heart behaves as a muscular tissue pump $[17,18]$.

The saturation of blood oxygen is the measurement of the percentage of oxygen available in the bloodstream. When the blood flows from the heart to the rest of the body, it passes through the lungs first, where the blood cells meet oxygen molecules $[19,20]$. For the development of the prototype, the option to conduct partial blood oxygen saturation measure- ments using $\mathrm{SpO}_{2}$, was considered. It was also considered in previous works [21-25]. In this case, pulse oximetry was conducted through the measurement of the oxygen transported by hemoglobin in the interior of the blood vessels; this was added to the measurement of the peripheral heart frequency and rhythm through the measurement of the partial oxygen saturation parameters and the HR [14,20].

This study focused on the development of $\mathrm{SpO}_{2}$ and $\mathrm{HR}$ measurements that will allow the monitoring and estimation in real time of the user's state and health related to the established parameters, all framed inside the trend of using even more energy-efficient devices that are also environmentally friendly, taking other developments as a reference point for heart rate telemonitoring using the $\mathrm{SpO}_{2}$ technique. For our case, the development of Bluetooth low-energy (BLE) devices was taken into account, which comply with lowcost and open-hardware solutions operated via http requests for data transmission and reception from a cloud server to an edge device. Finally, the required network performance assessment was conducted to guarantee the availability and integrity of the acquired values and signals.

\section{Case Description}

To obtain the blood oxygen saturation $\left(\mathrm{SpO}_{2}\right)$, and $\mathrm{HR}$ signals for oximetry, the sensor used was MAXREFDES117\#. This sensor is an optical HR monitor and pulse oximeter; it features the MAX30102 with integrated red and IR LEDs for $\mathrm{HR}$ and $\mathrm{SpO}_{2}$ detection, with $1.8 \mathrm{~V}$ power, LED color reading, infrared LED, and delivery of data via $\mathrm{I} 2 \mathrm{C}$ with an approximate value of US $\$ 20$. To achieve the reading of the variables, a reading sequence was established, as shown in Figure 1.

Once the reading sequence was established, the architecture for the system of acquisition, transmission, and monitoring of the signals of the IoT system was formulated (See Figure

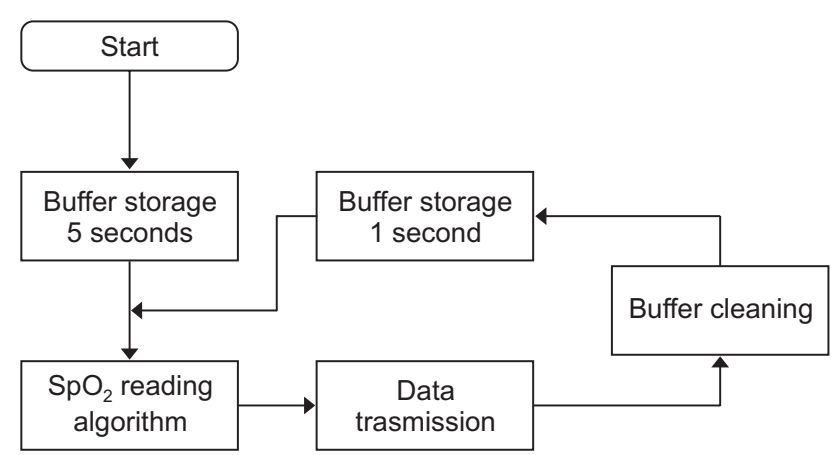

Figure 1. Acquisition sequence of $\mathrm{SpO}_{2}$ and heart rate data. 


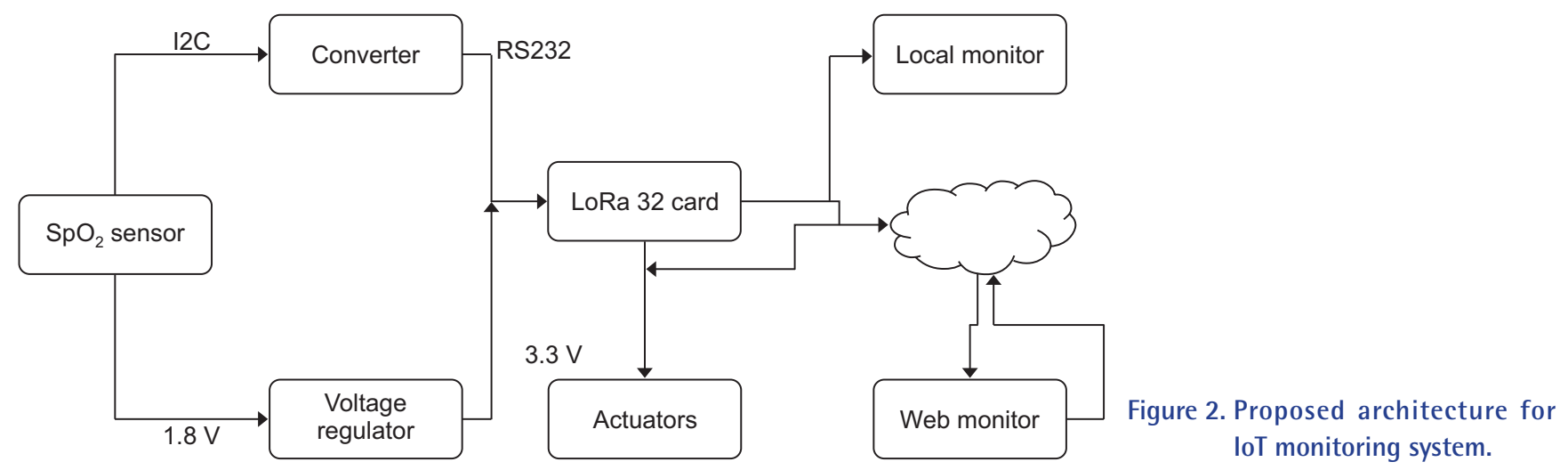

Table 1. Heltec card specifications

\begin{tabular}{ll}
\hline \multicolumn{1}{c}{ Part } & \multicolumn{1}{c}{ Characteristic } \\
\hline Microcontroller & ESP32 TensilicaLX6 dual-core processor \\
LoRa & SX1278 \\
Wi-Fi bandwidth & $150 \mathrm{Mbps}$ \\
Display & OLED 0.96-inch \\
Bluetooth & BLE low-power dual-mode Bluetooth \\
\hline
\end{tabular}

Table 2. Measured heart rate (HR) and $\mathrm{SpO}_{2}$

\begin{tabular}{cccc}
\hline & $\begin{array}{c}\text { Validation of the } \\
\text { HR measurement } \\
\text { (HRValid) }\end{array}$ & $\mathrm{SpO}_{2}$ & $\begin{array}{c}\text { Validation of the } \\
\mathrm{SpO}_{2} \text { measurement } \\
\left(\mathrm{SpO}_{2} \text { Valid }\right)\end{array}$ \\
\hline $\mathrm{HR}=87$ & 1 & 43 & 1 \\
\hline
\end{tabular}

2). Subsequently, a Wi-Fi LoRa 32 card model, manufactured by Heltec-China, was used for the implementation, with an approximate value of US $\$ 20$. It provided the advanced LoRa spread spectrum communication technology, transmission reception of ultra-long-distance and low-power-consumption BLE. Table 1 shows the specifications of the Heltec card.

The calculation from the $\mathrm{SpO}_{2}$ is based on Equation (1), where the determination of the $\mathrm{K}_{1}, \mathrm{~K}_{2}$, and $\mathrm{K}_{3}$ constants is required, which depend on the records from previous measurements. At start time, the system takes readings and stores the records for exactly 5 seconds, as seen in Figure 1:

$S p O_{2}=K_{1} \times(\text { Avg radius })^{2}+K_{2} \times($ Avg radius $)+K_{3}$

Where $\mathrm{SpO}_{2}$ is calculated through the average radius, this average radius is calculated, with the average ratio of IR and red LED [16]. The average is obtained from the infrared LEDs and the $\mathrm{K}_{1}, \mathrm{~K}_{2}$, and $\mathrm{K}_{3}$ constants, as previously explained. It is important that for the average calculation, 25 readings are made. The measurements delivered by the car-
Table 3. Fields of loT health table in database management system

\begin{tabular}{llc}
\hline \multicolumn{1}{c}{ Field } & \multicolumn{1}{c}{ Type } & Extent \\
\hline IdSensor & Whole & 256 \\
KeySensor & Whole & 256 \\
TimeStampServer & Date & - \\
IdGroup & Whole & 256 \\
Variable & Varchar & 256 \\
Value & Float & 256 \\
Alarm & Timestamp & - \\
\hline
\end{tabular}

diac monitoring system correspond to the readings from the red LED, infrared LED, validation of the measurement, HR and $\mathrm{SpO}_{2}$, as shown in Table 2 .

An actuator with two states, normally closed-NC and normally open-NO, was used for the activation once the monitoring system detected a heart rate under 70 beats or over 90 beats per minute, this according to the HR interval maximum and minimum provided by specialized personnel in the physical performance center where the tests were carried out.

The results obtained from the four measurements and their corresponding validations are sent through LoRa, which supports the frequency bands of $433-470 \mathrm{MHz}$ and $868-915$ $\mathrm{MHz}$ with the maximum sensitivity of $-139 \mathrm{dBm}$. The communication distance of the measured open area is $3.6 \mathrm{~km}$ (packet loss rate $<0.3 \%$; Wi-Fi up to data rate: $150 \mathrm{Mbps}$ @11n HT40,72 Mbps@11n HT20, 54 Mbps @ 11 g, 11 Mbps @ 11 band $200 \mathrm{~m}$ of distance), the last BLE up to 35 $\mathrm{m}$, with a consumption of $20 \%$ less, on average, than the two reference systems. The saving in energy consumption was obtained in comparison to other oximeters models available on the market. As a comparison case, the jzk-301 presented an average consumption of $90 \mathrm{~mW}$, the ESAMACT with a consumption of $108 \mathrm{~mW}$, while the proposed system had an average consumption of $76 \mathrm{~mW}$. The system operates via an 
HTTP request made to the server. These results are stored in a database implemented in MySQL through a PHP script. Data is stored in its corresponding table called IoT health as seen in Table 3.

The data is available in the server and visualized via the web. Measurement parameters were obtained for the availability and performance of the prototype and connectivity with the server where the remote monitoring and control module is. The assessed metrics were the following: endto-end delay, latency, jitter, and throughput. Figure 3 shows the end-to-end calculated delay from the beginning of the capture of the variable to the received confirmation from the server. Figure $3 \mathrm{~A}$ shows how the initial events when establishing their connection with the server, present a delay of over $30 \mathrm{~ms}$, but once the connection time passes, the delays tend to remain under $30 \mathrm{~ms}$. Figure $3 \mathrm{~B}$ shows the network latency, which matches the network delays shown in Figure 3A. According to what it shows regarding the initial connection times with the server, the latency is elevated, but once the connection is established, latency decreases. Finally,

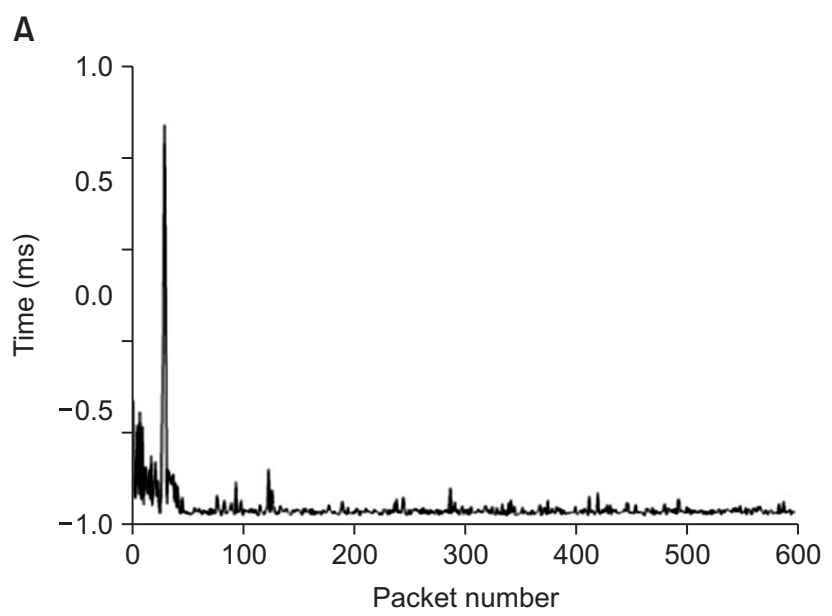

B

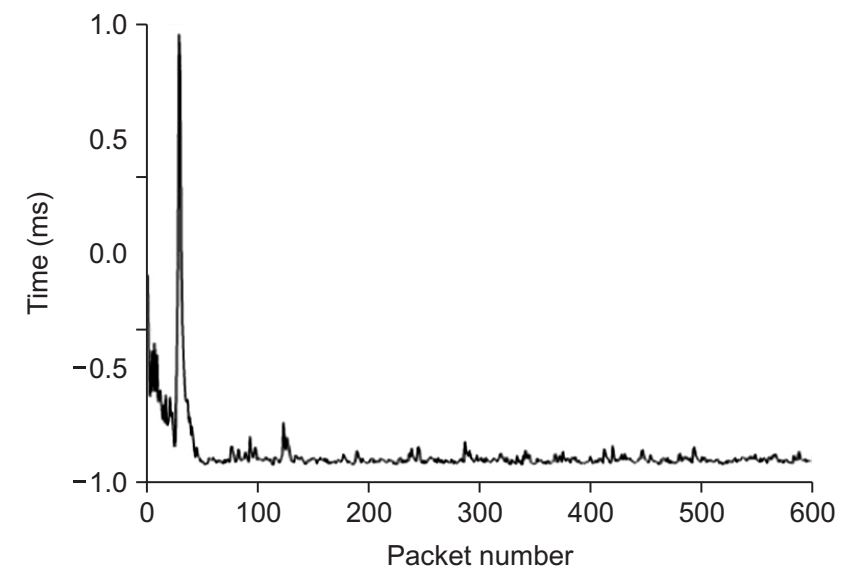

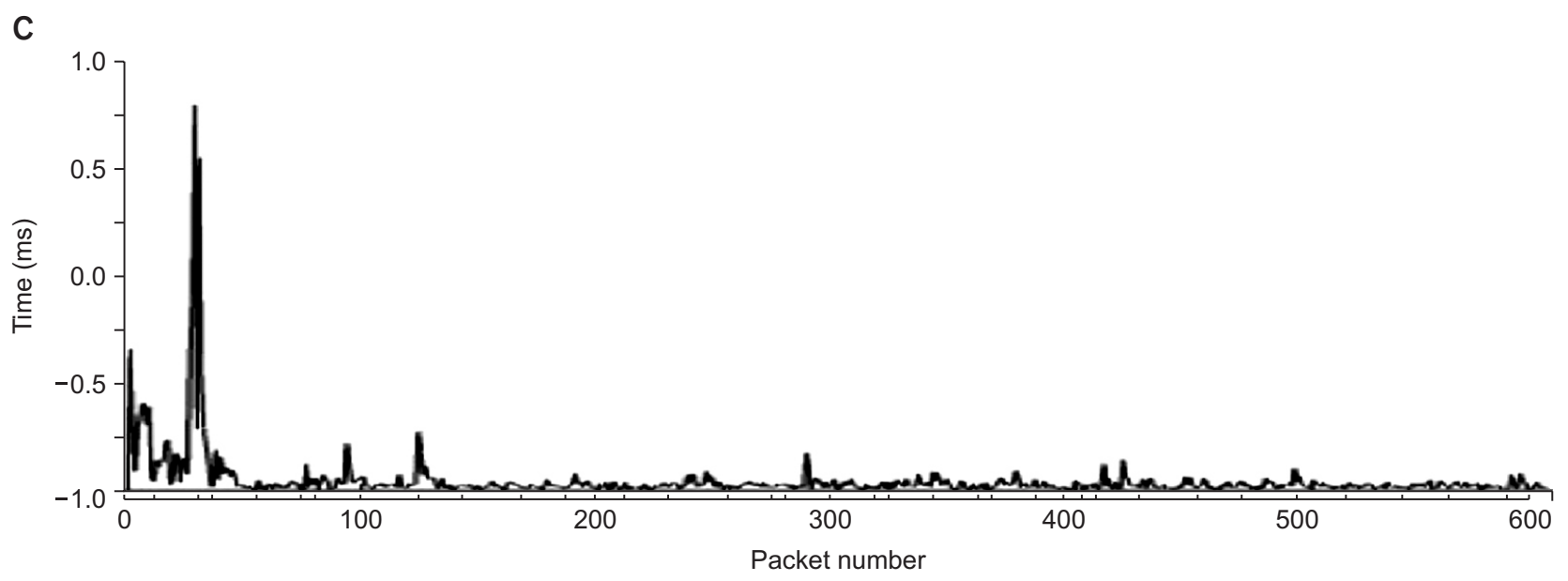

Figure 3. The assessed metrics: (A) end-to-end delay, (B) latency, and (C) jitter. 
Table 5. Comparison of two reference devices

\begin{tabular}{llcc}
\hline & Accuracy (\%) & Mean & Standard deviation \\
\hline Device 1 & $P|\varepsilon| \leq 5$ & 91 & 4 \\
& $P|\varepsilon| \leq 5$ & 7 & 2 \\
Device 2 & $P|\varepsilon| \leq|\varepsilon| \leq 5$ & 2 & 5 \\
& $P|\varepsilon| \leq 5$ & 90 & 5 \\
& $P 10 \leq|\varepsilon| \leq 5$ & 9 & 4 \\
\hline
\end{tabular}

devices on the market. The first was the MD300C20_OTC oximeter manufactured by Omron-India; the second device was an ESAMACT LED fingerprint oximeter, manufactured by ESAMACT-China; all validation was done under controlled laboratory conditions. A hundred local readings were conducted per device during six reading sessions for the same individual. The results are shown in Table 5.

Results from the comparison of such two reference devices were obtained from three precision bands: lower to $5 \%$, between $5 \%$ and $10 \%$, and higher than $10 \%$. In these two cases, the system achieved at least $90 \%$ success for $5 \%$ lower precision regarding both devices. The results are shown in Table 5.

\section{Discussion}

The work done in this study allowed the verification of the possible implementation of IoT systems in the health sector and home healthcare through open hardware, with a visualization error of $1 \%$ and latency times under $600 \mathrm{~ms}$.

The visualized results and the average measured percentage errors, allow the verification of the system's efficiency, which may indicate an opportunity for the analysis and processing of medical data for the subsequent construction of control, forecast, and estimation methods for patients receiving healthcare or healthy individuals in real time.

Due to the characteristics of the used components, greater port availability for the activation of a greater number of actuators and controllers is possible. This contributes to the prevention of events, control of the user's body variables, control of environmental variables, and effective follow-up after medical procedures.

Measurements obtained by this low-cost hardware were always above $90 \%$ at the highest precision interval. This allows us to conclude that these open, low-cost systems are a real alternative to the existing systems with the potential to provide higher access to services and resources at lower costs.

\section{Conflict of Interest}

No potential conflict of interest relevant to this article was reported.

\section{Acknowledgments}

This research has been funded by the Office of the Vice Rector for Research at Universidad Militar Nueva Granada (Project No. INV-ING-2365).

\section{ORCID}

Leonardo Juan Ramirez Lopez (https://orcid.org/0000-0002-6473-5685) Gabriel Puerta Aponte (https://orcid.org/0000-0003-1730-170X) Arturo Rodriguez Garcia (https://orcid.org/0000-0002-8383-6561)

\section{References}

1. Son LP, Thu NT, Kien NT. Design an IoT wrist-device for SpO2 measurement. Proceedings of 2017 International Conference on Advanced Technologies for Communications (ATC); 2017 Oct 18-20; Quy Nhon, Vietnam. p. 144-9.

2. Lee I, Lee K. The Internet of Things (IoT): applications, investments, and challenges for enterprises. Bus Horiz 2015;58(4):431-40.

3. Vogler M. Efficient IoT application delivery and management in smart city environments [dissertation]. Wien, Austria: Technische Universitat Wien; 2016.

4. Valdivieso Caraguay AL, Benito Peral A, Barona Lopez LI, Garcia Villalba LJ. SDN: evolution and opportunities in the development IoT applications. Int J Distrib Sens Netw 2014;10(5):735142.

5. Ma HD. Internet of Things: objectives and scientific challenges. J Comp Sci Technol 2011;26(6):919-24.

6. Atzori L, Iera A, Morabito G. Understanding the Internet of Things: definition, potentials, and societal role of a fast evolving paradigm. Ad Hoc Netw 2017;56:122-40.

7. Chiang M, Zhang T. Fog and IoT: an overview of research opportunities. IEEE Internet Things J 2016;3(6): 854-64.

8. Kelly SD, Suryadevara NK, Mukhopadhyay SC. Towards the implementation of IoT for environmental condition monitoring in homes. IEEE Sens J 2013;13(10):3846-53.

9. Al-Fuqaha A, Guizani M, Mohammadi M, Aledhari M, Ayyash M. Internet of Things: a survey on enabling technologies, protocols, and applications. IEEE Com- 
mun Surv Tutor 2015;17(4):2347-76.

10. Wang J, Li D. Adaptive computing optimization in software-defined network-based industrial Internet of Things with fog computing. Sensors (Basel) 2018;18(8):2509.

11. Ibarra-Lancheros KS, Puerto-Leguizamon G, Suarez-Fajardo C. Quality of service evaluation based on network slicing for software-defined $5 \mathrm{G}$ systems. TecnoLogicas 2018;21(43):27-41.

12. Sundararaman LV, Edwards RR, Ross EL, Jamison RN. Integration of mobile health technology in the treatment of chronic pain: a critical review. Reg Anesth Pain Med 2017;42(4):488-98.

13. Severinghaus JW. Takuo Aoyagi: discovery of pulse oximetry. Anesth Analg 2007;105(6 Suppl):S1-4.

14. Aarrestad S, Qvarfort M, Kleiven AL, Tollefsen E, Skjonsberg $\mathrm{OH}$, Janssens JP. Diagnostic accuracy of simple tools in monitoring patients with chronic hypoventilation treated with non-invasive ventilation; a prospective cross-sectional study. Respir Med 2018;144:30-5.

15. Song S, Jiang F, Hao L, Xu L, Yi X, Li G, et al. Use of bi-level pulsed frequency-division excitation for improving blood oxygen saturation precision. Measurement 2018;129:523-29.

16. O'Leary RJ Jr, Landon M, Benumof JL. Buccal pulse oximeter is more accurate than finger pulse oximeter in measuring oxygen saturation. Anesth Analg 1992;75(4):495-8.

17. Arruza J, Alzate R. Esfuerzo percibido y frecuencia cardiaca: El control de la intensidad de los esfuerzos en el entrenamiento de judo. Revista de Psicologia del Deporte 2007;5(2):29-40.

18. Mendonca F, Mostafa SS, Morgado-Dias F, Navarro-
Mesa JL, Julia-Serda G, Ravelo-Garcia AG. A portable wireless device based on oximetry for sleep apnea detection. Computing 2018;100(11):1203-19.

19. Laborde M. Medida de la Saturacion de Oxigeno por Medio Optico [Internet]. Montevideo, Uruguay: Universidad de la Republica; 2004 [cited at 2019 Jun 30]. Available from: http://www.nib.fmed.edu.uy/laborde. pdf.

20. Muncharaz AB, Andres EB, Valero RR, Font SM, Tuson RC, Campos RA. Relationship between pulse oximetry and determination of arterial oxygen saturation. Influence of vasoactive drugs on the SattcO2-SatO2 correlation. Med Intensiva 2001;25(9):333-9.

21. Chan C, Inskip JA, Kirkham AR, Ansermino JM, Dumont G, Li LC, et al. A smartphone oximeter with a fingertip probe for use during exercise training: usability, validity and reliability in individuals with chronic lung disease and healthy controls. Physiotherapy 2018 Oct 26 [Epub]. https://doi.org/10.1016/j.physio.2018.07.015.

22. Gong G, Guo Y, Sun X, Wang X, Yin Y, Feng DD. Study of an oxygen supply and oxygen saturation monitoring system for radiation therapy associated with the active breathing coordinator. Sci Rep 2018;8(1):1254.

23. Jones GA, Ray S, Ramnarayan P, Peters MJ. Error without trials: Safe $\mathrm{SpO}(2)$ threshold levels may not be derivable from $\mathrm{SpO}(2)-\mathrm{PaO}(2)$ relationships. J Crit Care 2017;40:283-4.

24. Al Rajeh AM, Hurst JR. Monitoring of physiological parameters to predict exacerbations of chronic obstructive pulmonary disease (COPD): a systematic review. J Clin Med 2016;5(12):108.

25. Kim JA. Book Review: The Internet of Healthy Things. Healthc Inform Res 2016;22(3):250. 